\title{
Role of community pharmacists in patients' self-care and self-medication
}

This article was published in the following Dove Press journal:

Integrated Pharmacy Research and Practice

24 June 2015

Number of times this article has been viewed

\section{Paul Rutter \\ School of Pharmacy, University of Wolverhampton, Wolverhampton, UK}

Correspondence: Paul Rutter School of Pharmacy, University of Wolverhampton, Wulfruna Street, Wolverhampton WVI ISB, UK

Tel +441902322I73

Email paul.rutter@wlv.ac.uk
Abstract: This review highlights the growing prominence of self-care and explores the contribution of community pharmacy. Firstly, background to self-care is discussed, followed by placing self-care in context with regard to the general public and accessing community pharmacy. From this perspective the contribution community pharmacy currently makes is assessed, paying particular attention to the factors that negatively impact on the ability of community pharmacy to facilitate self-care.

Keywords: community pharmacy, health promotion, disease prevention, health maintenance, health belief

\section{What is self-care?}

Fundamentally, the concept "self-care" puts responsibility on individuals for their own health and well-being. Many authors have described what constitutes self-care, and whilst no universally agreed definition exists, it is clear that self-care is seen as a broad concept that encompasses activities to establish and maintain health, through to preventing ill health. ${ }^{1}$ The World Health Organization defines self-care as "the ability of individuals, families and communities to promote health, prevent disease, and maintain health and to cope with illness and disability with or without the support of a health-care provider". ${ }^{2}$

In its broadest sense, self-care is therefore any action or activity individuals or communities do to maintain both physical and mental health. Many authors have investigated people's perception of health and illness and how that might manifest into taking action. ${ }^{3-6}$ This will vary enormously and depend on how individuals perceive themselves and the environment around them. People tend to weigh up the benefit they attach to good health versus the "cost" of accomplishment, as has been encapsulated in the "health belief" model."

Self-care has been described as a continuum (Figure 1), starting with individual choices on health (eg, taking exercise), moving through to managing their own ill health (eg, self-medicating) either on their own or with help. As people progress along the continuum, more facilitation by others is required until a person needs fully managed care.

\section{What is self-medication?}

"Self-medication" is just one element of self-care and can be defined as the selection and use of medicines by individuals to treat self-recognized illness 


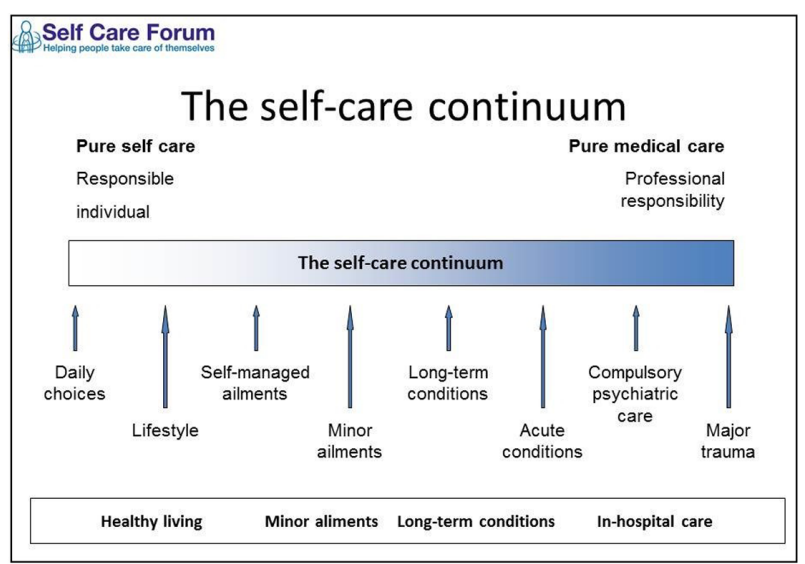

Figure I The self-care continuum. ${ }^{102}$

Note: Copyright $(\subset$ 2015. Reproduced from the Self Care Forum.

or symptoms. How these medicines are made available to the public varies from country to country but all have been approved by regulatory agencies as safe and effective for people to select and use without the need for medical supervision or intervention. Products come with comprehensive labeling, and evidence suggests that the majority of consumers will read this information before taking a new medicine. ${ }^{8}$ Whether the decisions made are correct is largely unknown.

Self-selection medicines are commonly referred to as "over-the-counter" medicines or "nonprescription" medicines. In this review, the term "nonprescription" will be adopted since different markets place varying restrictions on their availability, but all fall under the umbrella term of "nonprescription".

\section{Facilitated self-medication}

The majority of purchases for nonprescription medicines are by the consumer alone using product information from packaging to make an informed decision on whether to purchase. When consumers seek help at the point of purchase, this can be termed "facilitated self-medication". Where medicines are purchased through pharmacies, staff are in a strong position to facilitate self-care decision making by consumers, as in most pharmacies the transaction takes place through a trained counter assistant or the pharmacist. Limited research has shown that consumer-purchasing decisions are affected by this "facilitation". Nichol et $\mathrm{al}{ }^{9}$ and Sclar et $\mathrm{al}^{10}$ both demonstrated that consumers ( $25 \%$ and $43 \%$, respectively) altered their purchasing decision when proactively approached by pharmacy students. Furthermore, a small proportion of consumers did not purchase anything (13\% and $8 \%$, respectively) or were referred to their doctor ( $1 \%$ and $4 \%$, respectively). ${ }^{9,10}$ These studies highlight how the pharmacy team is able to positively shape consumer decisions and help guide consumers to alternative (and arguably better) alternatives.

\section{The prominence of self-care}

Self-care is not new; people have always taken an active role in their own health. What is different now is the attitude toward self-care by policy makers, health care organizations, not-for-profit agencies, and frontline health care workers. Health improvements have been seen in people adopting health-enhancing behaviors rather than just through medical intervention. This has led to self-care being seen in a broader context than just the way in which people deal with everyday illness. Of course, health outcomes are not the only reason why there has, and continues to be, a resurgence in self-care. Twenty-five years ago, Coons spoke of increasing health care costs, changes in societal lifestyle, improved educational levels, and increasing consumerism - all as valid today as they were then. ${ }^{11}$ Fundamentally, there are two major drivers affecting self-care: consumerism and costs.

\section{Consumerism}

As Coons discussed, changes in society have led to people having a different outlook on health and the way in which individuals perceive their own health/ill health. ${ }^{11}$ Yet today's world is very different to that experienced by Coons, especially with regard to access to information. The creation of the Internet and almost instantaneous access to limitless data on all aspects of health and care means that people across the globe have the means to query decisions and challenge medical opinion. This growing empowerment is also influenced by greater levels of education; having information is one thing but being able to understand it and utilize it is another. This has proved challenging to health care systems and workers, having to move from traditional structures and paternalistic doctrines (eg, "doctor knows best") to a patient-focused and -centered type of care. For example, medicine taking has shifted from compliance to adherence, ${ }^{12}$ and medical consultations now advocate "shared decision making". ${ }^{13}$ This heightened public awareness about health, in the context of self-care, allows individuals to make informed choices and recognize that much can be done by themselves. The extent of self-care is none better exemplified than by the level of consumer self-medication. The use of nonprescription medicines is the most prevalent form of medical care in the world. ${ }^{14}$ Sales are huge, with the global market estimated to be worth $€ 73$ billion. Markets in Western Europe and the USA make up almost half of all sales, but growth in these markets has slowed - even so, the average spend per capita in Western 
Europe is $€ 68$. Emerging markets in Central and Eastern Europe, the People's Republic of China, Russia, and India now represent major growth areas for nonprescription medicines. Fuelled by these markets, nonprescription medicines have seen greater sales growth than that of prescription medicines since $2008 .^{15}$

Understanding consumer-purchasing patterns in such a large market is vital to the pharmaceutical industry, but equally as important to community pharmacy, both from the point of view of maximizing revenue and having the opportunity to provide facilitated self-medication. Despite the enormous sums of money spent on nonprescription medicines, approximately only $25 \%$ of people regularly purchase nonprescription medicines (25\% tend to seek medical attention, and 50\% do nothing). ${ }^{16-18}$ The extent to which this happens does vary from country to country, and in some markets this is considerably higher - for example, in South Africa and the USA, where $35 \%-40 \%$ of people use nonprescription medications on a regular basis. ${ }^{8}$

Most people have high levels of confidence in the products they take, believing them to be effective and as good as prescription medicines. ${ }^{19,20}$ This seems to stem from prior positive use of the product, with most consumers using the same product for subsequent episodes of the same illness. In effect, they build up a small "formulary" of trusted medicines. ${ }^{18,21}$

These factors seem to be unaffected by country or time. Reports spanning 30 years have repeatedly concluded that these play an important part in consumer decision making, and are probably the major reason why consumers buy nonprescription medicines. ${ }^{22,23}$ The element of convenience does have a country context - for example, in Western countries, this is primarily due to ease of access that negates the need for doctor seeking, which is often associated with higher cost and increased time. In developing countries, "convenience" is more associated with "need" due to lower levels of health infrastructure and access to medical resources. ${ }^{8}$

Although, some differences exist in why nonprescription medicines are bought, the range of signs and symptoms experienced by people is not country specific. It appears that minor illnesses have no geographic boundaries and the same problems are seen the world over. Respiratory problems (coughs, colds, sore throats), pain disorders (headache, musculoskeletal), and gastrointestinal disturbances are three therapeutic areas that consistently rank as the most prevalent problems seen in all markets and this is reflected in product sales data. ${ }^{8}$ The way in which consumers decide on particular courses of action is primarily influenced by the perception of symptoms experienced, severity, and duration. ${ }^{24-26}$ Market research surveys have highlighted that consumers strongly exhibit certain health-seeking behaviors depending on the signs and symptoms experienced. For example, bleeding from the rectum is almost exclusively associated with consulting a doctor, as too are symptoms like arthritis, cystitis, and those of a depressive type. ${ }^{27}$ In contrast, headache, indigestion, coughs and colds, minor skin problems (eg, insect bites, sunburn) are mostly self-treated with no advice from any health care professional. ${ }^{8,15,19}$ Consumers therefore attach "seriousness" to symptoms and act according to the perceived level of seriousness.

\section{Costs}

As populations across the globe begin to live longer, whether through better hygiene, nutrition, or advances in medicine, the provision of medical care is becoming more and more expensive. ${ }^{28}$ In an attempt to control costs, many countries have gone through major health care reforms to maximize existing both financial and human resources to deliver effective and efficient health care. ${ }^{29-32}$ These reforms include integrating self-care into mainstream public health policy, including the management of long-term conditions.

We already know that patients self-manage problems to a large extent, ${ }^{33}$ but encouraging more people to exercise greater levels of self-care, either for acute or chronic problems, has the potential to shift costs away from professional care, as minor changes in behavior have significant potential to affect demand for formal health care.

Figures from the UK give some indication as to the magnitude of potential cost savings. Take primary care workload as an example. It is reported that approximately $20 \%-40 \%$ of general practice (GP) workload constitutes patients seeking help for minor illness. ${ }^{34}$ Pillay et al attempted to quantify cost savings to the UK National Health Service if minor ailment consultations were transferred to community pharmacy rather than being seen in GP. ${ }^{35}$ An estimated 57 million consultations were categorized as being for minor illness presentations. Factoring staff and medicine costs, they conservatively estimated that the economic burden to the National Health Service was $£ 2$ billion. Whilst shifting all such consultations away from GP is unrealistic, even if a small proportion of patients could be managed via self-care then cost savings would be very considerable. Utilization of health care resources where self-care could have been exercised has also been noted for accident and emergency presentations. Bednall et al estimated that $8 \%$ of attendees $(n=2,636)$ could have been managed through a community pharmacy. ${ }^{36}$ 
Findings from a recent UK commissioned report that the relative costs for accessing different levels of health care were significantly cheaper through pharmacy services (£29 compared with $£ 82$ for GP and $£ 147$ for emergency hospital visits). ${ }^{37}$

\section{Contribution of community pharmacy to self-care}

Community pharmacists are uniquely placed to provide support and advice to the general public compared with other health care professionals. The combination of location and accessibility means that most consumers have ready access to a pharmacy where health professional advice is available on demand. A high level of public trust and confidence in pharmacists' ability to advise on nonprescription medicines is afforded to community pharmacists. ${ }^{38}$ Although there is a general global move to liberalize nonprescription markets, pharmacies in many countries still are the main suppliers of nonprescription medicines. ${ }^{15}$ Pharmacists are therefore in a position to facilitate consumer self-care and self-medication, which needs to be built on and exploited.

\section{Managing minor illness - medicine reclassification}

Global health care policy, as previously mentioned, now has a strong self-care focus and various strategies have been put in place to encourage consumers (and pharmacists) to have a more active role in exercising self-care.

The most notable long-term global health care policy, which directly affects pharmacy, is the reclassification of prescription-only medicines as nonprescription medicines. ${ }^{39-43}$ In many countries (eg, Australia, New Zealand, France, Sweden, Canada, UK) regulatory frameworks support reclassification by having a gradation in the level of medicine availability, whereby certain medicines can only be purchased at a pharmacy. These "pharmacy medicines" usually have to be sold either by the pharmacist or under their supervision. Other countries operate a two-category system (prescription/ nonprescription), such as that seen in the USA. Over the last 30 years this approach has seen a wide range of therapeutic agents made available to consumers, including emergency hormonal contraception (and in 2015, ellaOne ${ }^{\circledR}$ [ulipristal acetate] will also be available in the European Union), proton pump inhibitors, triptans, and beta-2-agonists.

Pharmacies unquestionably handle and manage large numbers of consumers who seek help and advice for minor illness, and advocates of pharmacy have argued that this will decrease doctor workload regarding minor illness, allowing them to concentrate more on "complex" patient care. To date, most reclassifications have involved medicines that are used to treat acute problems. However, recent reclassifications have strayed into the area of medicines for the management of long-term conditions. Statins, orlistat, and tamsulosin are now available in some markets. ${ }^{44}$ These medicines may herald the beginning of a new era in nonprescription availability, whereby pharmacists will be able to manage longterm conditions.

The expansion of nonprescription medicines has undoubtedly contributed to the growth seen in the market and given consumers greater choice. It has also provided community pharmacy with an opportunity to demonstrate real and tangible benefits to consumers by facilitating patient self-care. However, research data on the impact community pharmacy has on patient outcomes through facilitated self-medication are lacking when compared with those on patient self-care. Yet in more formalized situations where community pharmacy delivers self-care, there is more credible research evidence to show the positive contribution it makes. For example, in the UK, government-endorsed (and -funded) schemes such as the minor ailment schemes and Healthy Living Pharmacies have shown the positive impact community pharmacy can have. ${ }^{45,46}$

\section{Barriers to community pharmacy exercising self-care}

Great strides have been made in recent years in transforming community pharmacy from "merely" dispensers and sellers of medicines. However, there is still a multitude of problems associated with increasing the contribution pharmacy makes to self-care. Many of these obstacles are unfortunately, though, of pharmacy's own making.

\section{Pharmacists as a barrier to self-care}

Is pharmacy ready to be seen by policy makers, consumers, and other health care providers as a credible alternative to delivering patient-focused services? It is first necessary to know how willing pharmacy is to practice change. Many countries have produced "road maps" or "blueprints" to becoming more patient focused, ${ }^{47-50}$ but translating these into actual practice has proven slow and problematic. ${ }^{51-57}$ For example, 10 years after the introduction of the Medicines Use Review in the UK, approximately only $75 \%$ of the total potentially available reviews had been performed. ${ }^{58}$ When looking at adoption of change and delivery of new services, it is unclear why they are not more universally adopted. However, as stated by Rogers ${ }^{59}$ in his book Diffusion of 
Innovations, typically only $2.5 \%$ of a population performs as innovators and $13.5 \%$ will be early adopters. Using this premise then, the majority of pharmacists will not be receptive to change even when provided with the right conditions. Research reporting on the introduction of new cognitive services often cites predictable barriers to practice change, including issues such as time, funding, and limited support. Rosenthal et al considered the culture of pharmacy to explain this reluctance to change. ${ }^{60}$ They argued that pharmacists' lack of confidence in their own clinical ability and fear of taking on responsibility and accountability are stifling the ability of the profession to take on these new challenges. This viewpoint appears to be grounded in reasonable evidence. Multiple studies that have investigated role extension or the provision of new services consistently report on pharmacists' self-assessment for the need for training and reluctance to make autonomous decisions. ${ }^{61-63}$

The literature seems to suggest that pharmacists themselves are a major barrier to adopting behaviors that would allow facilitated self-care and self-medication.

\section{Pharmacists' inability to facilitate self-care}

Regardless of what degree of control is placed on medicine availability in different countries, pharmacists can now manage and treat a wider number of conditions than ever before. This raises the question as to whether pharmacists are capable of selling these medicines appropriately. Early research into pharmacist-consumer interactions in pharmacy practice did not address this but concentrated more on auditing questioning behavior and analyzing the advice people received. This body of work did illustrate the basic nature of performance - the types of question asked, frequency of advice provided, and consumer perception to questioning. The findings were broadly critical of pharmacist performance. ${ }^{64-69}$ Over the same time period, covert investigation by the UK consumer organization Which? also concluded that pharmacists generally performed poorly. ${ }^{70-72}$ Further practice research (mainly from developed countries) has sought to determine the outcomes rather than the mechanics of the interactions. Findings from all papers raise questions over pharmacist ability. Lamsam and Kropff found that in a third of interactions the pharmacists made recommendations without assessing the patient's symptoms and in a further third of cases recommendations were poor, which could have potentially caused harm. ${ }^{73}$ Rutter et al found that the expected outcome was only reached in half of observed cases. ${ }^{74}$ Driesen and Vandenplas ${ }^{75}$ and Bilkhu et $\mathrm{al}^{76}$ also reported poor performance, and each study (on diarrhea in a baby and allergic conjunctivitis in an adult, respectively) suggested that too few questions were asked. Tucker et al compared pharmacist performance with that off doctors and nurses across a spectrum of dermatological conditions. ${ }^{77}$ Pharmacists performed more poorly than doctors and only $40 \%$ of pharmacists were able to identify all lesions correctly. ${ }^{77}$ Data from developing countries are limited but a review by Brata et al also highlighted inconsistent information gathering leading to inappropriate recommendations. ${ }^{78}$ The use of protocols/guidelines and mnemonics seems to have been almost universally adopted by pharmacy, yet performance using these "decision aids" seems to have little impact on improving performance. ${ }^{79-84} \mathrm{~A}$ recent review of mnemonics by Shealy concluded that "ultimately, use of these tools can aid the provider in obtaining information from patients in immediate need circumstances, and improve the quality of care". ${ }^{85}$ These tools might allow for standardizing the information gained from the patient; the more important question, however, is how do pharmacists utilize that information? Having a set of data still requires that dataset to be interpreted - this is where the problem seems to lie. Recent research findings on investigating pharmacist diagnostic decision making have shown that community pharmacists show poor clinical reasoning due to over reliance on protocol-driven questioning. ${ }^{86-88}$

In attempt to drive standards up, some pharmacy organizations employ mystery shopper techniques to monitor standards of practice. ${ }^{89}$ Compounding these findings of suboptimal performance is with whom the interaction occurs. Most consultations are solely handled by non-pharmacist staff, who have been shown to perform more poorly than pharmacists. ${ }^{23,90-93}$ It would seem logical, then, to involve the pharmacist earlier and more frequently in consultations. This raises questions over the level of importance placed on differing pharmacy tasks and the appropriate use of staff in community pharmacies. Data over the last 20 years suggest that pharmacists still spend the largest amount of their time in non-patient-focused activity ${ }^{94}$ Undoubtedly this is dictated, in large part, by prescription volume, but it also suggests a reluctance to move out of the dispensary.

It appears that pharmacists' ability to consistently and appropriately facilitate self-care through managing people requesting advice on signs and symptoms has improved little over the last 25 years. ${ }^{95}$

Despite pharmacy's own failings, the operating environment in which pharmacy contributes to self-care also poses major challenges. Community pharmacy is at the interface 
between consumer self-care and managed care, and often acts as a filtering mechanism between the two. Unfortunately, this remains almost exclusively an informal arrangement between pharmacy and primary medical services. This hinders facilitated self-medication and acceptance from doctors toward community pharmacists delivering more patient-focused care. Overall, doctors are very receptive to pharmacists providing greater levels of support to medicine-specific tasks (eg, assisting with compliance, providing medicines information, cost-effective prescribing). However, it appears they are less willing to endorse services, which are traditionally associated with GP. ${ }^{62}$

Specific to self-medication, doctors (and nurses to a lesser extent) have been canvassed about the wider availability of medicines. Broadly speaking doctors have become, over time, more supportive of wider medicine availability. ${ }^{96-99}$ Similar views have been noted for nurses with prescribing rights. ${ }^{100}$ This is especially true for deregulated medicines to treat acute conditions. In contrast, doctors and nurses are much more reluctant to accept nonprescription availability of medicines to treat chronic conditions. ${ }^{96-99}$ For both groups of health care professionals, major doubts exist over the pharmacist's ability to have the necessary information from which to make decisions and conduct subsequent monitoring after initial medicine supply. These strong beliefs mean that in the shortterm it seems unlikely that management by pharmacists of patients with long-term conditions will happen unless more integrated and formal mechanisms of sharing information are established. One possible solution to overcome these reservations would be to draw on models of medicine supply elsewhere. For example, countries such as New Zealand and Australia have an "intermediary" category of medicine that has to be sold by the pharmacist. ${ }^{101}$ This system could provide the reassurances required by other health care practitioners that adequate safeguards were in place for the patient to be successfully managed through the pharmacy.

\section{Conclusion}

Pharmacy has a long history of facilitating self-care, but now more than ever before pharmacists and their staff are being provided opportunities to expand their contribution. Yet considerable barriers still exist if community pharmacy is to maximize its potential. From within the profession, questions have to be asked about pharmacists' ability and readiness to embrace change. From other health care providers, the issue is one of reluctance to allow pharmacy to take on greater responsibility. New health care pathways providing easier transition through the self-care continuum that bring the consumer, pharmacist, and primary medical services together are needed.

\section{Disclosure}

The author declares no conflicts of interest in this work.

\section{References}

1. Webber D, Guo Z, Mann S. Self-care in health: we can define it, but should we also measure it? Self Care. 2013;4(5):101-106.

2. World Health Organization (WHO) Regional Office for South-East Asia. Self-care in the Context of Primary Health Care: Report of the Regional Consultation Bangkok, Thailand, 7-9 January 2009. New Delhi: WHO Regional Office for South-East Asia; 2009. Available from: apps.searo.who.int/PDS_DOCS/B4301.pdf. Accessed January 31, 2015 .

3. Blaxter M. Health and Lifestyles. London and New York, NY: Routledge; 1990.

4. Nettleton S. The Sociology of Health and Illness. Cambridge: Polity Press; 2006.

5. Mechanic D. Medical Sociology. 2nd ed. New York, NY: Free Press; 1978.

6. Monaghan LF. Looking good, feeling good: the embodied pleasures of vibrant physicality. Sociol Health Illn. 2001;23(3):330-356.

7. Scambler G. Sociology as Applied to Medicine. 5th ed. Edinburgh: Saunders; 2003:1.

8. World Self-Medication Industry (WSMI). Responsible Self-Care and Self-Medication: A Worldwide Review of Consumer Surveys. Ferney-Voltaire: WSMI; nd. Available from: http://www.wsmi.org/ wp-content/data/pdf/wsmibro3.pdf. Accessed February 9, 2015.

9. Nichol MB, McCombs JS, Johnson KA, Spacapan S, Sclar DA. The effects of consultation on over-the-counter medication purchasing decisions. Med Care. 1992;30(11):989-1003.

10. Sclar DA, Robison LM, Skaer TL. Pharmacy consultation and overthe-counter medication purchasing outcomes. Over-the-Counter Medication Intervention Project Team. J Clin Pharm Ther. 1996;21(3): $177-184$.

11. Coons SJ. The pharmacist's role in promoting and supporting self-care. Holist Nurs Pract. 1990;4(2):37-44.

12. Aronson JK. Compliance, concordance, adherence. Br JClin Pharmacol. 2007;63(4):383-384.

13. Barry MJ, Edgman-Levitan S. Shared decision making - pinnacle of patient-centered care. N Engl J Med. 2012;366(9):780-781.

14. Covington TR. The pharmacist as nonprescription drug therapy manager: let's seize the opportunity. J Am Pharm Assoc (Wash). 2002;42(3):518-519.

15. Tisman A. The Rising Tide of OTC in Europe: Trends, Challenges and New Potential in a Rapidly Evolving Market. Norwalk, CT: IMS Health; 2010. Available from: http://www.imshealth.com/deployedfiles/imshealth/ Global/Content/Healthcare/Healthcare\%20Solutions/Consumers/ The_Rising_Tide_Of_OTC_Europe.pdf. Accessed January 23, 2015.

16. Martins AP, da Costa Miranda A, Mendes Z, Soares MA, Ferreira P, Nogueira A. Self-medication in a Portuguese urban population: a prevalence study. Pharmacoepidemiol Drug Saf. 2002;11(5): 409-414.

17. Chui WK, Li SC. Advice-giving on self-medication: perspectives of community pharmacists and consumers in Singapore. J Clin Pharm Ther. 2005;30(3):225-231.

18. Proprietary Association of Great Britain (PAGB). A Summary Profile of the OTC Consumer. London: PAGB; 2005. Available from: http:// www.pagb.co.uk/publications/pdfs/Summaryprofile.pdf. Accessed April 8, 2015.

19. Banks I. Self care of minor ailments: a survey of consumer and healthcare professional beliefs and behaviour. Self Care. 2010;1(1): $1-13$. 
20. Hassali MA, Shafie AA, Al-Qazaz H, Tambyappa J, Palaian S, Hariraj V. Self-medication practices among adult population attending community pharmacies in Malaysia: an exploratory study. Int J Clin Pharm. 2011;33(5):794-799.

21. Gray NJ, Cantrill JA, Noyce PR. 'Health repertories': An understanding of lay management of minor ailments. Patient Educ Couns. 2002;47(3): 237-244.

22. Thomas DH, Noyce PR. The interface between self medication and the NHS. BMJ. 1996;312(7032):688-691.

23. Akesson C, Paulos C, Marin F, Salazar C. A description of patients presenting with minor illness in community pharmacies in southern Chile. Int J Pharm Pract. 2007;15(2):123-128.

24. Cantrill J, Morris C, Weiss M. How patients perceive minor illness and factors influencing seeing a doctor. Prim Health Care Res Dev. 2006; 7(2):157-164

25. Cornford CS. Why patients consult when they cough: a comparison of consulting and non-consulting patients. Br J Gen Pract. 1998;48(436): 1751-1754.

26. Wyke S, Hewison J, Russell IT. Respiratory illness in children: what makes parents decide to consult? Br J Clin Pract. 1990;40(335): 226-229.

27. Stoller EP, Forster LE, Portugal S. Self-care responses to symptoms by older people. A health diary study of illness behavior. Med Care. 1993;31(1):24-42.

28. Blumenthal D, Davis K, Guterman S. Medicare at 50-moving forward. N Engl J Med. 2015;372(7):671-677.

29. Black N. Can England's NHS survive? N Engl J Med. 2013;369(1): $1-3$.

30. Keyhani S, Falk R, Howell EA, Bishop T, Korenstein D. Overuse and systems of care: a systematic review. Med Care. 2013;51(6): 503-508.

31. Marchildon G. Canada: Health system review. Health Syst Transit. 2013;15(1):1-179.

32. Ministry of Health. Better, Sooner, More Convenient Health Care in the Community. Wellington: Ministry of Health; 2011. Available from: http://www.health.govt.nz/system/files/documents/publications/bettersooner-more-convenient-health-care_0.pdf. Accessed February 17, 2015.

33. National Health Service (NHS) England. Transforming Urgent and Emergency Care Services in England: Urgent and Emergency Care Review End of Phase 1 Report; High Quality Care for All, Now and for Future Generations. London: NHS England; 2014. Available from: http://www.nhs.uk/nhsengland/keogh-review/documents/uecr. ph1 report.fv.pdf. Accessed February 16, 2015.

34. PAGB. Unlocking Self Care: PAGB Annual Review 2008. London: PAGB; 2008.

35. Pillay N, Tisman A, Kent T, Gregson J. The economic burden of minor ailments on the National Health Service (NHS) in the UK. Self Care. 2010;1(3):105-116.

36. Bednall R, McRobbie D, Duncan J, Williams D. Identification of patients attending accident and emergency who may be suitable for treatment by a pharmacist. Fam Pract. 2003;20(1):54-57.

37. Pharmacy Research UK. Community Pharmacy Management of Minor Illness: MINA Study. Final Report. London: Pharmacy Research UK; 2013. Available from: http://www.pharmacyresearchuk.org/waterway/ wp-content/uploads/2014/01/MINA-Study-Final-Report.pdf. Accessed February 17, 2015.

38. Pharmacists near top of "most trusted profession" poll. Pharm J. 2009;282:472.

39. Cohen JP, Paquette C, Cairns CP. Switching prescription drugs to over the counter. BMJ. 2005;330(7481):39-41.

40. Harrington P, Shepherd MD. Analysis of the movement of prescription drugs to over-the-counter status. J Manag Care Pharm. 2002;8(6): 499-508.

41. Lipsky MS, Waters T. The "prescription-to-OTC switch" movement. Its effects on antifungal vaginitis preparations. Arch Fam Med. 1999;8(4): 297-300.
42. Lynd LD, Taylor J, Dobson R, Willison DJ. Prescription to over-thecounter deregulation in Canada: are we ready for it, or do we need to be? CMAJ. 2005;173(7):775-777.

43. Soller RW. Evolution of self-care with over-the-counter medication. Clin Ther. 1998;20 Suppl C:C134-C140.

44. WSMI. Switch: Prescription to Non-Prescription Medicines Switch. Ferney-Voltaire: WSMI; 2009. Available from: http://www.wsmi.org/wpcontent/data/pdf/wsmi_switchbrochure.pdf. Accessed March 23, 2015.

45. Brown D, Portlock J, Rutter P, Nazar Z. From community pharmacy to healthy living pharmacy: positive early experiences from Portsmouth, England. Res Social Adm Pharm. 2014;10(1):72-87.

46. Paudyal V, Watson MC, Sach T, et al. Are pharmacy-based minor ailment schemes a substitute for other service providers? A systematic review. Br J Gen Pract. 2013;63(612):e472-e481.

47. Department of Health. Pharmacy in England: Building on Strengths Delivering the Future. Cm 7341. Norwich: The Stationery Office; 2008. Available from: https://www.gov.uk/government/uploads/ system/uploads/attachment_data/file/228858/7341.pdf. Accessed February 17, 2015.

48. Canadian Pharmacists Association (CPhA) Task Force on a Blueprint for Pharmacy. Blueprint for Pharmacy: Designing the Future Together. Ottawa, ON: CPhA; 2008. Available from: http://www.pharmacists. ca/index.cfm/pharmacy-in-canada/blueprint-for-pharmacy/. Accessed February 17, 2015.

49. Pharmacy Sector Action Group. Focus on the Future: Ten-Year Vision for Pharmacists in New Zealand; 2004-2014. Wellington: Pharmaceutical Society of New Zealand; 2004. Available from: http://psnz.org.nz/ public/home/documents/10_yea_plan.pdf. Accessed February 17, 2015.

50. National Center for Chronic Disease Prevention and Health Promotion. Guide for Public Health: Partnering with Pharmacists in the Prevention and Control of Chronic Diseases. Atlanta, GA: Centers for Disease Control and Prevention; 2012. Available from: http://stacks.cdc.gov/ view/cdc/12103/cdc_12103_DS1.pdf. Accessed February 17, 2015.

51. Farris KB, Schopflocher DP. Between intention and behavior: an application of community pharmacists' assessment of pharmaceutical care. Soc Sci Med. 1999;49(1):55-66.

52. Tsuyuki RT, Schindel TJ. Leading Change in Pharmacy Practice: Fully Engaging Pharmacists in Patient-Oriented Healthcare. Edmonton, AB: University of Alberta Centre for Community Pharmacy Research and Interdisciplinary Strategies; 2004. Available from: https://www.epicore. ualberta.ca/compris/Docs/Leading\%20Change\%20FIP\%2012-2004. pdf. Accessed April 9, 2015.

53. Bradley F, Elvey R, Ashcroft D, Noyce P. Commissioning services and the new community pharmacy contract: (2) Drivers, barriers and approaches to commissioning. Pharm J. 2006;277:189-192.

54. Bradley F, Elvey R, Ashcroft D, Noyce P. Commissioning services and the new community pharmacy contract: (3) Uptake of enhanced services. Pharm J. 2006;277:224-226.

55. Scahill SL, Carswell P, Harrison J. An organizational culture gap analysis in 6 New Zealand community pharmacies. Res Social Adm Pharm. 2011;7(3):211-223.

56. Willink DP, Isetts BJ. Becoming 'indispensable': developing innovative community pharmacy practices. J Am Pharm Assoc (2003). 2005;45(3): 376-386.

57. Roberts AS, Benrimoj SI, Chen TF, Williams KA, Aslani P. Practice change in community pharmacy: quantification of facilitators. Ann Pharmacother. 2008;42(6):861-868.

58. Pharmaceutical Services Negotiating Committee (PSNC). MUR statistics [web page on the Internet]. London: PSNC; 2015. Available from: http://psnc.org.uk/funding-and-statistics/nhs-statistics/mur-statistics/. Accessed February 4, 2015.

59. Rogers EM. Diffusion of Innovations. 5th ed. New York, NY: Free Press; 2003.

60. Rosenthal M, Austin Z, Tsuyuki RT. Are pharmacists the ultimate barrier to pharmacy practice change? Can Pharm J (Ott). 2010; 143(1):37-42. 
61. Pfleger DE, McHattie LW, Diack HL, McCraig DJ, Stewart DC. Views, attitudes and self-assessed training needs of Scottish community pharmacists to public health practice and competence. Pharm World Sci. 2008;30(6):801-809.

62. Bryant LJM, Coster G, Gamble GD, McCormick RN. General practitioners' and pharmacists' perceptions of the role of community pharmacists in delivering clinical services. Res Social Adm Pharm. 2009; 5(4):347-362.

63. Paudyal V, Hansford D, Cunningham S, Stewart D. Over-the-counter prescribing and pharmacists' adoption of new medicines: diffusion of innovations. Res Social Adm Pharm. 2013;9(3):251-262.

64. Anderson C, Alexander A. Response to dysmenorrhoea: an assessment of pharmacists' knowledge and its application in practice. Int J Pharm Pract. 1993;2(3):180-183.

65. Krska J, Greenwood R, Howitt EP. Audit of advice provided in response to symptoms. Pharm J. 1994;252:93-96.

66. Krska J, Kennedy E. Responding to symptoms: Comparing general practitioners and pharmacists' advice. Pharm J. 1996;257:322-324.

67. Krska J, Kennedy EJ. An audit of responding to symptoms in community pharmacy. Int J Pharm Pract. 1996;4(3):129-135.

68. Morris CJ, Cantrill JA, Weiss MC. "One simple question should be enough": consumers' perceptions of pharmacy protocols. Int J Pharm Pract. 1997;5(2):64-71.

69. Morrow N, Hargie O, Donnelly H, Woodman C. "Why do you ask?" A study of questioning behaviour in community pharmacist-client consultations. Int J Pharm Pract. 1993;2(2):90-94.

70. Consumers' Association. Pharmacists: how reliable are they? Which Way to Health? 1991;12:191-194.

71. Consumers' Association. Vital checks are still not being made. Which Way to Health? 1994;12:196.

72. Consumers' Association. Counter advice. Which Way to Health? 1999;3:22-25.

73. Lamsam GD, Kropff MA. Community pharmacists' assessments and recommendations for treatment in four case scenarios. Ann Pharmacother. 1998;32(4):409-416.

74. Rutter PM, Horsley E, Brown DT. Evaluation of community pharmacists' recommendations to standardized patient scenarios. Ann Pharmacother. 2004;38:1080-1085.

75. Driesen A, Vandenplas Y. How do pharmacists manage acute diarrhoea in an 8-month-old baby? A simulated client study. Int J Pharm Pract. 2009;17(4):215-220.

76. Bilkhu P, Wolffsohn JS, Taylor D, Gibson E, Hirani B, Naroo SA. The management of ocular allergy in community pharmacies in the United Kingdom. Int J Clin Pharm. 2013;35(2):190-194.

77. Tucker R, Patel M, Layton AM, Walton S. An examination of the comparative ability of primary care health professionals in the recognition and treatment of a range of dermatological conditions. Self Care. 2013;4(4):87-89.

78. Brata C, Gudka S, Schneider CR, Everett A, Fisher C, Clifford RM. A review of the information-gathering process for the provision of medicines for self-medication via community pharmacies in developing countries. Res Social Adm Pharm. 2013;9(4):370-383.

79. Aradottir HA, Kinnear M. Design of an algorithm to support community pharmacy dyspepsia management. Pharm World Sci. 2008;30(5): 515-525.

80. Bertsche T, Nachbar M, Fiederling J, et al. Assessment of a computerised decision support system for allergic rhino-conjunctivitis counselling in German pharmacy. Int J Clin Pharm. 2012;34(1):17-22.

81. Cantrill JA, Weiss MC, Kishida M, Nicolson M. Pharmacists' perceptions and experiences of pharmacy protocols: a step in the right direction? Int J Pharm Pract. 1997;5(1):26-32.
82. Watson MC, Bond CM, Grimshaw J, Johnston M. Factors predicting the guideline compliant supply (or non-supply) of non-prescription medicines in the community pharmacy setting. Qual Saf Health Care. 2006; 15(1):53-57.

83. Schneider CR, Gudka S, Fleischer L, Clifford RM. The use of a written assessment checklist for the provision of emergency contraception via community pharmacies: a simulated patient study. Pharm Pract (Granada). 2013;11(3):127-131.

84. Schneider CR, Emery L, Brostek R, Clifford RM. Evaluation of the supply of antifungal medication for the treatment of vaginal thrush in the community pharmacy setting: a randomized controlled trial. Pharm Pract (Granada). 2013;11(3):132-137.

85. Shealy KM. Mnemonics to assess patients for self-care: is there a need? Self Care. 2014;5(1):11-25.

86. Akhtar S, Rutter P. Pharmacists thought processes in making a differential diagnosis using a gastro-intestinal case vignette. Res Social Adm Pharm. Epub September 28, 2014.

87. Rutter PM, Patel J. Decision making by community pharmacists when making an over-the-counter diagnosis in response to a dermatological presentation. Self Care. 2013;4(6):125-133.

88. Iqbal N, Rutter P. Community pharmacists reasoning when making a diagnosis: a think-aloud study. Int J Pharm Pract. 2013;21(S2): $17-18$.

89. Tan AC, Emmerton L. Non-prescription medicines: current issues in Australian community pharmacy. Int J Pharm Pract. 2009;17(4): 207-213.

90. Bissell P. Variation within community pharmacy. 2: responding to the presentation of symptoms. $J$ Soc Adm Pharm. 1997;14(2):105-115.

91. Emmerton L, Shaw J. The influence of pharmacy staff in non-prescription medicine sales. Int J Pharm Pract. 2002;10(2):101-106.

92. Stevenson M, Taylor J. The effect of a front-shop pharmacist on NPM consultations. J Soc Adm Pharm. 1995;12(3):154-158.

93. Ward PR, Bissell P, Noyce PR. Medicines counter assistants: roles and responsibilities in the sale of deregulated medicines. Int J Pharm Pract. 1998;6(4):207-215.

94. Hassell K, Seston EM, Schafheutle EI, Wagner A, Eden M. Workload in community pharmacies in the UK and its impact on patient safety and pharmacists' well-being: a review of the evidence. Health Soc Care Community. 2011;19:561-575.

95. Can you trust your local pharmacy's advice? Which? investigation finds best and worst companies. Which? [website on the Internet]. 2013 May 20. Available from: http://www.which.co.uk/news/2013/05/can-you-trustyour-local-pharmacys-advice-319886/. Accessed March 17, 2015.

96. Morley A, Jepson MH, Edwards C, Stillman P. What do doctors think of pharmacists treating minor ailments? Pharm J. 1983;231:387.

97. Spencer JA, Edwards C. Pharmacy beyond the dispensary: general practitioners' views. BMJ. 1992;304(6843):1670-1672.

98. Erwin JN, Britten N, Jones R. General practitioners' views on over the counter sales by community pharmacists. BMJ. 1996;312(7031): 617-618.

99. Bayliss E, Rutter P. General practitioners' views on recent and proposed medicine switches from POM to P. Pharm J. 2004;273:819-821.

100. Rutter PM, Tsang G. Nurse independent prescribers' views on recent and proposed medicine switches. Nurse Prescribing. 2011;9(4): 195-199.

101. Aronson JK. From prescription only to over-the-counter medicines ('PoM to P'): time for an intermediate category. Br Med Bull. 2009;90:63-69.

102. Self Care Forum. The self-care continuum. Available from: http://www. selfcareforum.org/about-us/what-do-we-mean-by-self-care-and-whyis-good-for-people/. Accessed June 16, 2015. 
Integrated Pharmacy Research and Practice

Dovepress

\section{Publish your work in this journal}

Integrated Pharmacy Research and Practice is an international, peer-reviewed, open access, online journal, publishing original research, reports, reviews and commentaries on all areas of academic and professional pharmacy practice. This journal aims to represent the academic output of pharmacists and pharmacy practice with particular focus on integrated care. All papers are carefully peer reviewed

Submit your manuscript here: http://www.dovepress.com/integrated-pharmacy-research-and-practice-journal to ensure the highest standards as well as ensuring that we are informing and stimulating pharmaceutical professionals. The manuscript management system is completely online and includes a very quick and fair peer-review system, which is all easy to use. Visit http://www.dovepress.com/testimonials.php to read real quotes from published authors. 